DOI: $10.19195 / 2082-8322.8 .9$

Kacper Kosma Kocur

Uniwersytet Wrocławski

\title{
System medialny współczesnego Izraela
}

Problematyka i funkcjonowanie współczesnego systemu medialnego obowiązującego w Izraelu to tematy rzadko poruszane w polskich publikacjach naukowych. Wśród powodów tego zaniedbania można wymienić różne aspekty, takie jak np.:

- napięta sytuacja polityczna, mająca miejsce już od proklamowania niepodległości Izraela w 1948 r., która odciskała się na próbach kształtowania systemu medialnego i utrudniała jego stabilizację — zagadnienie pozostawało więc otwarte i trudne do naukowego opracowania;

- stosunki polityczne i społeczne pomiędzy Polską a Izraelem — obecne w Polsce lat 50. i 60. nastroje antysemickie powodowały zwiększoną emigrację polskich Żydów do Izraela, a kulminację wzajemnej niechęci obu państw stanowiło zerwanie stosunków dyplomatycznych z Izraelem w 1967 r. oraz zamknięcie izraelskiej ambasady;

- niechęć i brak potrzeby poznania tematu.

Biorąc pod uwagę przedstawione argumenty, a dodatkowo odległość geograficzną, należy stwierdzić, że brak zainteresowania kształtującym się systemem medialnym w nowym państwie pozostawał uzasadniony i zrozumiany. Sytuacja zmieniła się w momencie przełomu politycznego w Polsce. W lutym 1990 r. nastąpiło bowiem ponowne nawiązanie stosunków dyplomatycznych pomiędzy Polską a Izraelem, w którym panował już stabilny i rzeczowy porządek medialny. Nowe odkrycia technologiczne i wzorce czerpane ze Stanów Zjednoczonych wpłynęły na jakość i kondycję izraelskiego systemu medialnego, jednak temat w dalszym ciągu nie budził zainteresowania polskich badaczy.

Należy tę lukę uzupełnić, biorąc pod uwagę nie tylko poprawę relacji pomiędzy Polską i Izraelem na poziomie politycznym, lecz także wzajemne, społeczne zainteresowanie. Polacy bowiem coraz częściej przybywają do Izraela w celach zarówno turystycznych, jak i ekonomicznych. Podobnie Izraelczycy odwiedzają Polskę już 
nie tylko ze względu na miejsca martyrologii, lecz również z zainteresowania polską kulturą i żywym rozwojem miejscowej społeczności żydowskiej. Zagłębienie się w system medialny w Izraelu jest jak najbardziej wskazane ze względu na: primo, możliwość poznania i oceny, w jaki sposób izraelskie media spełniają swoje funkcje (informacyjną, rozrywkową, opiniotwórczą, kulturalną i kontrolną), secundo, wykorzystania tej wiedzy w branży medialnej w Polsce.

Zaczynając od grup medialnych, najważniejsze funkcjonujące w Izraelu to:

1. Yedioth Ahronoth Group z siedzibą w Tel-Awiwie, pod zarządem Arnona Mozesa. Do tej grupy należą gazety: „Yedioth Ahronoth”, „Calcalist” i „Vesti”, magazyny tematyczne: „Blazer”, „Mentha”, „LaIsha” i „Pnai Plus”, telewizja Yedioth Tishkoret, wydawnictwo książkowe Yedioth Books, agencja modelingu Look i serwisy internetowe: Ynet.co.il i Ynetnews.com.

2. The Jerusalem Post Group z siedzibą w Jerozolimie, której dyrektorem generalnym jest Yaron Aher. Należy do niej gazeta "The Jerusalem Post” wraz z dodatkami kulturalnymi i lokalnymi oraz serwisy internetowe: JPost.com i JPost TV Daily News. Jednym z udziałowców grupy jest Eli Azur, współwłaściciel darmowej gazety „Israel Post", wydawanej przez Metro Israel Ltd.

3. Haaretz Media Group z siedzibą w Tel-Awiwie. Jej dyrektorem generalnym jest Rami Guez. Do grupy należą gazety „Haaretz” i „The Marker” oraz serwisy internetowe: Haaretz.com i TheMarker.com.

Najbardziej popularnym medium w Izraelu jest prasa. Według badań z 1992 r. $85,5 \%$ dorosłej populacji Izraela czytało wówczas gazety codzienne ${ }^{1}$.

Ustawa zasadnicza Izraela gwarantuje wolność mediów, w tym prasy, jednak aby móc wydawać gazetę, należy mieć pozwolenie Ministerstwa Spraw Wewnętrznych. Władze izraelskie mogą odmówić pozwolenia na założenie tytułu prasowego, jeżeli potencjalny redaktor naczelny nie spełnia któregoś z wymogów. Należą do nich: ukończenie 25. roku życia, posiadanie dokumentu potwierdzającego odpowiednie wykształcenie oraz brak przeszłości kryminalnej ${ }^{2}$. W latach 2006-2016 rząd Izraela odmówił pozwolenia na wydawanie ok. 62 gazet, wydał natomiast 459 pozwolen ${ }^{3}$.

W 2016 r. w Izraelu było wydawanych 14 ogólnokrajowych dzienników:

1. „Haaretz”, założony w 1919 r.;

2. „The Jerusalem Post”, założony w 1932 r.;

3. „Yedioth Ahronoth”, założony w 1939 r.;

4. „Al-Ittihad”, założony w 1944 r.;

5. „Maariv”, założony w 1948 r.;

6. „Hamodia”, założony w 1950 r.;

${ }^{1}$ S. Lehman-Wilzig, A. Schejter, Mass Media in the Middle East: A Comprehensive Reference Guide, Westport 1994, s. 111. Jeśli nie podano inaczej, tłumaczenia z języka angielskiego - K.K.K.

2 D. Dolev, Interior Ministry has a stranglehold on the publication of newspapers in Israel, 16.01.2016, http://www.haaretz.com/israel-news/.premium-1.697682 (dostęp: 17.05.2016).

${ }^{3}$ Ibidem. 
7. „Globes”, założony w 1983 r.;

8. „Yated Ne’eman”, założony w 1985 r.;

9. „Courier”, założony w 1991 r.;

10. „Vesti”, założony w 1992 r.;

11. „Israel Hayom”, założony w 2007 r.;

12. „Israel Post”, założony w 2007 r.;

13. „Calcalist”, założony w 2008 r.;

14. „The Marker”, założony w $2008 \mathrm{r}$.

Wskazane tytuły w większości są hebrajskojęzyczne, w mniejszej części arabsko-, angielsko-, francusko- i rosyjskojęzyczne.

Czasopismo społeczno-polityczne „Haaretz” należy do grupy medialnej Haaretz Group i jest wydawane na terenie obecnego Izraela najdłużej — od 1919 r. Dziennik ukazuje się w językach hebrajskim (w Izraelu) i angielskim (w Stanach Zjednoczonych). Znajdują się w nim teksty polityczne, takie jak artykuły na temat bieżących wydarzeń, wiadomości czy komentarze, lecz także felietony, recenzje książek, filmów, muzyki i spektakli teatralnych, reportaże, teksty o zdrowiu, kulinariach, religii, problemach żydowskich i arabskich. Z dziennikiem związanych jest kilkudziesięciu cenionych publicystów, m.in. Amos Harel, Akiva Eldar, Aluf Benn, Daniel Rogov, Daniel Ben Simon, Danny Rubinstein, Sayed Kashua, Meron Benvenisti oraz Uri Klein. Redaktorem naczelnym od 2011 r. jest izraelski dziennikarz Aluf Benn, współpracujący wcześniej z takimi gazetami, jak „,The New York Times”, „The Guardian”, „Foreign Affairs” i „Newsweek”. Średni nakład dziennika „Haaretz” to 72 tys. egzemplarzy, a w weekendy - ponad 100 tys. egzemplarzy. Według badań Target Group Index (TGI; izraelska agencja badawcza) z 2015 r. 4,6\% respondentów deklaruje, że czyta tę gazetę regularnie, co plasuje „Haaretz” na czwartym miejscu pod względem poczytności ${ }^{4}$. Dziennik posiada również wydanie internetowe w serwisie Haaretz.com. Ponadto w 2008 r. usamodzielniono dodatek ekonomiczny „The Marker”, na skutek czego stał się on osobnym dziennikiem, wciąż funkcjonującym w ramach Haaretz Group. Pismo to zawiera teksty poświęcone różnym aspektom biznesowym, ekonomicznym i finansowym, również dotyczącym nowych technologii i opieki zdrowotnej.

„The Jerusalem Post”, należący do grupy medialnej The Jerusalem Post Group, to dziennik ukazujący się od 1932 r. Wydawany jest w językach angielskim oraz francuskim. Pierwotnie miał charakter lewicowy i sympatyzował z Partią Pracy, jednak jego polityczna orientacja zmieniła się pod zarządem Kanadyjczyka - Conrada Blacka, który uczynił czasopismo bardziej konserwatywnym ${ }^{5} .16$ listopada 2004 r. „The Jerusalem Post” został sprzedany firmie Mirkaei Tikshoret, która stara się zachować bezstronność polityczną. Wśród publicystów związanych z tym tytułem na-

${ }^{4}$ I. Hayom, TGI Poll: Israel Hayom expands lead as Israel's most read paper, 23.06.2015, http://www. israelhayom.com/site/newsletter_article.php?id=27061 (dostęp: 18.05.2016).

${ }^{5}$ B. Reich, H. Goldberg, Historical Dictionary of Israel, Lanham 2008, s. 256. 
leży wymienić m.in. Gila Troya, Jonathana Rosenbluma, Malenie Phillips, Isi Leibler, Warrena Goldsteina, Alana Dershowitza i Gershona Baskina. Redaktorem naczelnym od 2016 r. jest Yakkov Katz - dziennikarz i były korespondent angielskiego tygodnika militarnego „Jane’s Defence Weekly” i amerykańskiego dziennika „USA Today”. Podobnie jak w „Haaretz”, w „The Jerusalem Post” można znaleźć zarówno teksty poświęcone polityce, jak i dotyczące kultury i tematów społecznych. Ponadto raz w miesiącu ukazuje się dodatek „Ivrit”, zawierający uproszczone lekcje języka hebrajskiego. Od 2008 r. „The Jerusalem Post” współpracuje z „The Wall Street Journal”, dzięki czemu w Izraelu wydawany jest biznesowo-ekonomiczny magazyn „The Wall Street Journal Europe”. Średni nakład dziennika „The Jerusalem Post” to 50 tys. egzemplarzy, a w weekendy -80 tys. egzemplarzy. Istnieje również wydanie internetowe w serwisie JPost.com.

„Yedioth Ahronoth” to hebrajskojęzyczny dziennik o profilu centrolewicowym, który ukazuje się od 1939 r. Należy do Yedioth Ahronoth Group, zarządzanej przez Arnona Mozesa. Gazeta jest opisywana jako ta, „która ludzkie interesy stawia ponad wyrafinowaną analizą", a jej właściciele charakteryzują ją jako „medium narodowe”. Treści w niej zawarte dotyczą polityki, spraw społecznych, kultury i rozrywki. Pojawiają się też m.in. komentarze, felietony i relacje. Redaktorem naczelnym jest Ron Yaron. „Yedioth Ahronoth” jest jedną z najpopularniejszych gazet w Izraelu, o czym świadczy nakład wynoszący 300 tys. egzemplarzy (w wypadku wydania tygodniowego) i 600 tys. egzemplarzy (w weekendy) oraz drugie miejsce w rankingu najpoczytniejszych gazet. Według badań TGI dziennik jest czytany regularnie przez 35,5\% respondentów ${ }^{7}$. Do grupy medialnej Yedioth Ahronoth należą również:

- hebrajskojęzyczny magazyn dla kobiet „LaIsha”, zawierający informacje o modzie, wizażu, kulturze i obyczajach, ukazujący się od 1947 r. Od 1950 r. czasopismo jest sponsorem wyborów Miss Izraela. Redaktorką naczelną jest Karina Shtotland. Nakład czasopisma wynosi ok. 50 tys. egzemplarzy;

— rosyjskojęzyczny dziennik „Vesti”, założony w 1992 r., zawierający informacje polityczne i kulturalne przeznaczone dla rosyjskojęzycznej mniejszości w Izraelu. Redaktorem naczelnym od 2014 r. jest Danny Spektor. Nakład szacuje się na poziomie 55 tys. egzemplarzy. Konkurencję dla „Vesti” stanowi rosyjskojęzyczny „Courier”, ukazujący się od 1991 r.;

- hebrajskojęzyczny dziennik ekonomiczny „Calcalist”, założony w 2008 r., stanowiący konkurencję dla związanego z Haaretz Group pisma „The Marker” oraz „Globes”. Pismo podzielone jest na cztery sekcje: bieżące wydarzenia, codzienne kolumny (wśród nich m.in. marketing, prawo, nowe technologie, wiadomości finansowe), wiadomości rynkowe oraz lifestyle. Redaktorem naczelnym jest Yoel Esteron. Inter-

${ }^{6}$ G. Wolfsfeld, Media and Political Conflict: News from Middle East, Cambridge 1997, s. 96.

${ }^{7}$ I. Hayom, op. cit. 
netowe wydanie (Calcalist.co.il) znajduje się na jedenastej pozycji najpopularniejszych izraelskich stron internetowych $\mathrm{z}$ wynikiem 740 tys. wyświetleń tygodniowo.

Izraelski „Globes” powstał w 1983 r. Jest hebrajskojęzycznym dziennikiem neutralnym politycznie, a udziały w nim mają dwie spółki: Fishman Group $(57,1 \%)$ oraz Haim Bar-On (42,9\%). Redaktorem naczelnym jest Haggai Golan. Tematyka poruszana w "Globes" dotyczy ekonomii i finansów. Czasopismo jest podzielone na trzy sekcje: Titles - zawierającą główne wiadomości; Capital markets $-\mathrm{z}$ informacjami giełdowymi; oraz Globes tonight - będącą dodatkiem rozrywkowym. Wśród dodatków do gazety można wymienić m.in. „Lady Globes” - ukazujący się raz w miesiącu dodatek dla kobiet, „Mantalk” - wydawany raz w miesiącu dodatek dla mężczyzn, „Nadlan” - cotygodniowa wkładka z informacjami o nieruchomościach, oraz "Firma” - comiesięczna wkładka zawierająca informacje o marketingu na Bliskim Wschodzie, gospodarce światowej i polityce finansowej Izraela. Nakład dziennika „Globes” wynosi 45 tys. egzemplarzy. Według badań TGI 4,6\% respondentów deklaruje regularne czytanie tego pisma, co plasuje dziennik na piątej pozycji w rankingu poczytności ${ }^{8}$.

„Yated Ne’eman” jest konserwatywnym dziennikiem zarządzanym przez partię Degel haTora ${ }^{9}$, z redakcją w mieście Bnei Brak. Jej nazwa stanowi akronim słów Yoman Da'at Torah, co znaczy 'codzienna opinia Tory'. Ukazuje się od 1985 r. w języku hebrajskim, od niedzieli do piątku. Do 2006 r. publikowano również wydanie weekendowe $\mathrm{w}$ języku angielskim, dystrybuowane na terenie Izraela, południowej Afryki i Wielkiej Brytanii. Treści ukazujące się w „Yated Ne’eman” są kontrolowane przez komisję rabinacką, która we wszystkich kwestiach musi stosować się do zaleceń rabinów Nissima Karelitza i Aharona Leiba Shteinmana, będących autorytetami w dziedzinie prawa żydowskiego w Bnei Brak. Zgodnie z pierwotnymi założeniami wynikającymi z poglądów twórcy dziennika, rabina Elzara Shacha, „Yated Ne’eman” jest negatywnie nastawiony do syjonizmu, zarówno religijnego, jak i świeckiego. Teksty ukazujące się $\mathrm{w}$ gazecie są $\mathrm{w}$ większości poświęcone tematom związanym ze społecznością żydowską, religią i studiowaniem Tory, zawierają analizy i interpretacje wydarzeń w Izraelu i na świecie z punktu widzenia ultraortodoksyjnego judaizmu i społeczności Haredim ${ }^{10}$. Według badań z 2005 r. dziennik był czytany przez 19\% żydów ultraortodoksyjnych w Izraelu ${ }^{11}$. Dzienny nakład wynosi 22 tys. egzemplarzy. Prowadzone jest również wydanie internetowe - Yated.com. Obecnym redaktorem naczelnym „Yated Neeman” jest rabin Pinny Lipschutz.

Dziennik „Hamodia” powstał w 1950 r. i podobnie jak „Yated Ne'eman” skupia wokół siebie środowisko żydów ultraortodoksyjnych. Jest oficjalnym organem pra-

\footnotetext{
${ }^{8}$ Ibidem.

${ }^{9}$ R.L. Torstick, Culture and Customs of Israel, Santa Barbara 2004, s. 71.

${ }^{10}$ Haredim - społeczność żydów ultraortodoksyjnych.

11 Y. Cohen, God, Jews and the Media: Religion and Israel's Media, London 2012, s. 87.
} 
sowym Agudat Israel — partii politycznej reprezentującej ideologię ortodoksyjnego judaizmu. Gazeta jest określana jako największa i najbardziej poczytna wśród pism związanych ze społecznością Haredim ${ }^{12}$. Jest wydawana w Jerozolimie w języku hebrajskim. Jednocześnie ukazują się codzienne i weekendowe wydania anglojęzyczne w Stanach Zjednoczonych, a także weekendowe wydania anglo- i francuskojęzyczne w Australii, Izraelu i Wielkiej Brytanii. Co ciekawe, redaktorem naczelnym dziennika jest Ruth Lichtenstein, córka rabina Yehudy Leiba Levina, który był twórcą „Hamodii”. Teksty publikowane w dzienniku prezentują punkt widzenia społeczności Haredim i dotyczą spraw politycznych, społecznych, religijnych i ekonomicznych. Ponadto weekendowe wydanie amerykańskie zawiera rozszerzony magazyn ilustrowany. W oryginalnej, izraelskiej wersji czytelnicy nie znajdą jednak informacji związanych z modą, sportem, kulturą i rozrywką. Dla przykładu — informacje na temat sportu pojawiają się wyłącznie, gdy np. lokalna drużyna sportowa odniesie międzynarodowy sukces ${ }^{13}$. Z gazetą związani są tacy dziennikarze, jak: rabin Dovid Kaplan, rabin Issamar Ginzberg, rabin Abraham Twerski, Israel Katzover czy Tziporah Heller. Edycja hebrajskojęzyczna ma nakład 28 tys. egzemplarzy, natomiast anglojęzyczna — kilka tysięcy. Prowadzone są dwa serwisy internetowe w języku angielskim - Hamodia.com oraz Hamodia.co.uk.

Hebrajskojęzyczny dziennik „Maariv” ukazuje się od 1948 r., jego redakcja mieści się w Tel-Awiwie. Jest drugi po "Yedioth Ahronoth” pod względem sprzedaży w Izraelu, a piąty po „Israel Hayom”, „Yedioth Ahronoth”, „The Jerusalem Post” i „Haaretz” pod względem poczytności $(4,2 \% \mathrm{w} 2015 \mathrm{r} \text {. })^{14}$. Obecnym właścicielem gazety jest Eli Azur, będący również współudziałowcem w „The Jerusalem Post”. Wyróżnione są dwie marki - „Maariv haShavua” (hebr. 'tydzień') - wydawana w tygodniu od poniedziałku do czwartku, i „Maariv Sof haShavua” (hebr. 'koniec tygodnia') - publikowana w weekendy. Orientacja polityczna dziennika jest centrowa, nastawiony jest krytycznie wobec rządów premiera Beniamina Netanjahu ${ }^{15}$. Tematyka poruszana w tekstach publikowanych w „Maariv” oscyluje wokół polityki, ekonomii, rozrywki i życia społecznego. Dostępne są liczne dodatki, pojawiające się w różne dni tygodnia: we wtorki i środy ukazuje się „Signon”, poświęcony wystrojowi wnętrz oraz modzie, w piątki - „Musafshabat”, zawierający komentarze polityczne, „Journal” poświęcony rozrywce i kulturze, „Asakim”, traktujący o finansach i ekonomii, oraz dodatek dla kobiet - „At”. Ponadto wydania weekendowe zawierają dodatek sportowy i informator kulturalny. Redaktorami naczelnymi są Doron Cohen i Golan Bar-Yosef, a do publicystów należą m.in. Yehonatan Geffen, Erel Segal, Ben-Dror Yemini, Tzipi

12 Ibidem, s. 75.

13 S.D. Baumel, Sacred Speakers: Language and Culture among the Haredim in Israel, New York 2005, s. 56.

${ }^{14}$ I. Hayom, op. cit.

${ }^{15} \mathrm{~N}$. Jaffay, Israeli media woes could boost Bibi, 23.10.2012, http://www.forward.com/news/163161/ israeli-media-woes-could-boost-bibi/ (dostęp: 18.05.2016). 
Hotovely, Menachem Ben i Avi Ratzon. Nakład „Maariv” wynosi ok. 90 tys. egzemplarzy. Prowadzone jest też wydanie internetowe - Maariv.co.il.

Gazeta „Al-Ittihad” powstała w 1944 r. Jest jedynym arabskojęzycznym dziennikiem ukazującym się w Izraelu. Funkcjonuje pod wpływem Maki - Nowej Listy Komunistycznej ${ }^{16}$, będącej pośrednio następczynią Komunistycznej Partii Izraela. Funkcję redaktora naczelnego sprawuje działaczka feministyczna - Aida Touma-Suleiman, a wśród publicystów związanych z gazetą można wymienić m.in. Mahmouda Darwisha, Salima Joubrana, Samiha al-Qasima oraz Tawfika Toubiego. Siedziba redakcji mieści się w Hajfie, a gazeta jest dystrybuowana na terenie całego Izraela. Subskrypcje są wysyłane również poza granice państwa. „Al-Ittihad” ma swoich korespondentów w Waszyngtonie, Moskwie, Londynie, Atenach, Tunisie oraz w Belgradzie. Tematyka poruszana $\mathrm{w}$ gazecie obejmuje takie zagadnienia, jak polityka, sztuka, sport, turystyka, zdrowie, istnieją także sekcje dla kobiet i mężczyzn. Amal Jamal w swojej książce na temat społeczności arabskiej w Izraelu napisał o „Al-Ittihad”: „Ta gazeta stała się wyjątkowym głosem, artykułującym to, co zostało powzięte przez przywództwo Komunistycznej Partii jako serce i dusza Arabów"17. Nakład dziennika oscyluje w granicach 12-15 tys. egzemplarzy. Gazeta istnieje też w wersji internetowej na stronie Aljabha.org.

„Israel Hayom” jest bezpłatnym hebrajskojęzycznym dziennikiem należącym do amerykańskiego przedsiębiorcy Sheldona Adelsona, z redakcją w Tel-Awiwie. Gazeta jest politycznie ukierunkowana centroprawicowo i przychylna premierowi Beniaminowi Netanjahu ${ }^{18}$. Redaktorem naczelnym jest Amos Regev, którego zastępcą jest Aharon Lapidot, natomiast za edycję bieżących wiadomości odpowiada Baruch Ron. Czytelnicy znajdują w dzienniku teksty dotyczące polityki i życia społecznego. "Israel Hayom" ukazuje się w nakładzie od 325 tys. (wydania tygodniowe) do 550 tys. (wydanie piątkowe) egzemplarzy i jest najchętniej czytaną gazetą przez Izraelczyków. Według badań TGI jest regularnie czytana przez $40,1 \%$ respondentów ${ }^{19}$. Wydanie internetowe (Israelhayom.com) jest prowadzone w językach hebrajskim i angielskim.

Inną bezpłatną gazetą wydawaną w Izraelu jest „Israel Post” - dziennik powstały w 2007 r., będący własnością Eliego Azura i Davida Weismana. Jest jednocześnie jedynym publikowanym w Izraelu pismem popołudniowym. Gazeta jest rozdawana w takich miejscach, jak supermarkety Blue Square, sklepy AM-PM oraz stacje benzynowe Dor-Alon. Część materiałów zamieszczanych w „Israel Post” pochodzi z anglojęzycznego wydania „The Jerusalem Post”. Redakcja dziennika mieści się w Tel-Awiwie, a redaktorem naczelnym jest Golan Bar Yosef. Gazeta znajduje się na trzecim

${ }^{16}$ M. Golani, A. Manna, Two Sides of the Coin: Independence and Nakba 1948, The Hague 2011, s. 129.

17 A. Jamal, The Arab Public Sphere in Israel: Media Space and Cultural Resistance, Bloomington 2009, s. 48 .

${ }^{18}$ E. Inbar, The Arab Spring, Democracy and Security: Domestic and International, London 2013, s. 138.

${ }^{19}$ I. Hayom, op. cit. 
miejscu w rankingu najchętniej czytanych czasopism w Izraelu. Według badań TGI regularne sięganie po „Israel Post” deklaruje 7,7\% respondentów ${ }^{20}$.

W Izraelu ukazują się również cztery ogólnokrajowe tygodniki:

1. „Kul Al-Arab”, założony w 1987 r.;

2. „Makor Rishon”, założony w 1997 r.;

3. „B’Sheva”, założony w 2002 r.;

4. „Al-Madina”, założony w $2004 \mathrm{r}$.

„Kul Al-Arab” to arabskojęzyczny tygodnik z redakcją w Nazarecie, ukazujący się od 1987 r. Jest najchętniej czytanym arabskojęzycznym periodykiem, wydawanym w Izraelu ${ }^{21}$. Nakład gazety wynosi 38 tys. egzemplarzy. Zgodnie z opinią BBC „Kul Al-Arab” jest „znana przede wszystkim jako gazeta chrześcijańska, ale starająca się dotrzeć do muzułmańskich czytelników"22. Gazeta uważana jest za obiektywną bywa równie krytyczna wobec polityki Izraela i Stanów Zjednoczonych, jak i Autonomii Palestyńskiej. Fayez al-Shitiwi, który jest współwłaścicielem tygodnika, zaznacza, że jego pismo sprzeciwia się okupacji, nieposzanowaniu praw człowieka oraz atakom terrorystycznym, a ponadto opowiada się za równymi prawami dla Arabów i budowaniem sprawiedliwego państwa ${ }^{23}$. Poza Fayezem al-Shitiwim udziały w gazecie posiada Mussa Hassadiya. Gazetą siostrzaną jest „Lady Kul Al-Arab”, przeznaczona dla kobiet. Prowadzony jest również serwis internetowy (Al-Arab.net), codziennie wyświetlany przez 45 tys. użytkowników.

Od 1997 r. ukazuje się „Makor Rishon”, centroprawicowy tygodnik wydawany w języku hebrajskim, zarządzany przez grupę „Israel Hayom”. Gazeta została stworzona z myślą o wykreowaniu przestrzeni do dyskusji dla izraelskich konserwatystów, która zachowywałaby wysoki poziom. W przeszłości większość dziennikarzy związanych z tym tygodnikiem była świecka, z czasem jednak pismo zaczęło być redagowane przez większą liczbę osób religijnych. Właściciele wolą jednak nazywać gazetę "nacjonalistyczną", a nie „ortodoksyjną" 24 . Redaktorem naczelnym jest Chaggai Segal. Tygodnik dzieli się na osiem sekcji: General news - zawierającą najważniejsze informacje, komentarze polityczne oraz artykuł na temat finansów, sportu i podróży; Yoman - obejmującą wywiady, artykuły i autorskie kolumny (m.in. poetycką kolumnę Tzura Ehrlicha, sekcję satyryczną „Brichat Hamochot” Gidona Dukova czy kolumnę polityczną redagowaną przez Sophię Ron-Moriah); Diykuan - z kolumnami kulinarnymi, motoryzacyjnymi oraz przeznaczonymi dla fanów gier komputerowych; Shabbat - poświęconą judaizmowi, a także żydowskiej filozofii i literaturze;

${ }^{20}$ Ibidem.

${ }^{21}$ L. Louer, To Be an Arab in Israel, New York 2007, s. 115.

22 BBC, The press in Israel, 26.01.2005, http://www.news.bbc.co.uk/2/hi/middle_east/4191515.stm (dostęp: 19.05.2016).

${ }^{23}$ Ibidem.

${ }^{24}$ Reconsidering Israel-Diaspora Relations, red. E. Ben-Rafael, J. Bokser Liwerant, Y. Gorny, Boston 2014, s. 147. 
Tzedek - sekcję prawną dotyczącą zarówno prawa świeckiego, jak i religijnego; Motzash - obejmującą tematy z zakresu lifestyle'u; Nashim — dodatek dla kobiet; Otiot — dodatek dla dzieci i młodzieży; Sukariot — dodatek dla dzieci w wieku przedszkolnym, zawierający kolorowanki, łamigłówki i wierszyki. Ukazuje się również wydanie internetowe - Makorrishon.co.il.

„B’Sheva” to powstały w 2002 r. tygodnik, publikowany w języku hebrajskim. Jego właścicielem jest Arutz Sheva, a redaktorem naczelnym - Emanuel Shilo. Tematyka prezentowana w tym piśmie jest typowo religijna. Głoszone poglądy są prawicowe, a wiadomości i komentarze przedstawiane $\mathrm{z}$ religijno-konserwatywnego punktu widzenia. Ukazuje się w nakładzie 130-140 tys. egzemplarzy i jest najpopularniejszą izraelską gazetą o tematyce religijnej.

Prasa arabskojęzyczna w Izraelu nie ogranicza się tylko do wymienionych tytułów. Istnieje również tygodnik „Al-Medina”, zarządzany przez Rana Asaliego. Ukazuje się od 2004 r. w dwóch edycjach: (1) północnej, z siedzibą w Hajfie, dystrybuowanej na terenie północnego Izraela w nakładzie 15 tys. egzemplarzy, pod redakcją Firasa Khatibiego, i (2) centralnej, z siedzibą w Tel-Awiwie, sprzedawanej na terenie środkowego Izraela w nakładzie 12 tys. egzemplarzy, pod redakcją Ghaleba Kiwana. Tematy poruszane w tym tygodniku dotyczą bieżących wiadomości, zdrowia, sportu, rozrywki, kultury i sztuki.

Oprócz wskazanych ogólnokrajowych dzienników i tygodników w Izraelu funkcjonuje kilkaset gazet lokalnych, ukazujących się w różnej częstotliwości ${ }^{25}$.

Niemniej popularne jest radio. W Izraelu działa 40 radiostacji. Zarejestrowanych radioodbiorników jest 3070 tys., więc średnio na 1000 mieszkańców przypada 517 radioodbiorników ${ }^{26}$.

Narodowym radiem w Izraelu jest „Kol Israel”, które powstało w 1948 r. po połączeniu istniejącego wówczas radia „Kol ha-Hagana” oraz „Kol Yerushalaim”, najstarszego żydowskiego radia, funkcjonującego od 1936 r. Było zarządzane przez Israel Broadcasting Aurhority (IBA) ${ }^{27}$, urząd powstały w 1951 r. Od 2017 r., po rozwiązaniu IBA, radio znajduje się pod kontrolą nowego organu — Israeli Broadcasting Corporation. Wszystkie audycje nadawane w radio „Kol Israel” są dostępne w Internecie metodą streamingu. W ramach działalności radia „Kol Israel” funkcjonują następujące kanały:

1. „Reshet Aleph” - kanał pierwszy, nadający ogólnotematyczne audycje oraz wiadomości;

2. „Reshet Bet” - kanał drugi, nadający bieżące informacje oraz wiadomości sportowe;

${ }^{25}$ P. Zygmunt, Różnorodność bez cenzury - media w Izraelu, 3.11.2009, http://www.psz.pl/168-archiwum/pola-zygmunt-roznorodnosc-bez-cenzury-media-w-izraelu (dostęp: 19.05.2016).

${ }^{26}$ Press Reference, Israel, http://www.pressreference.com/Gu-Ku/Israel.html (dostęp: 19.05.2016).

27 OECD, Competition Law and Policy in Israel, Paris 2011, s. 81. 
3. „Reshet Gimel” — kanał trzeci, prezentujący izraelską muzykę, a także bieżące wiadomości;

4. „Reshet Dalet” - kanał czwarty, transmitujący informacje polityczne i kulturalne w języku arabskim;

5. „Reka” - kanał międzynarodowy, przeznaczony dla mieszkańców diaspory zainteresowanych zamieszkaniem w Izraelu, nadawany w czternastu językach: angielskim, francuskim, perskim, bukhori, jidysz, hiszpańskim, arabskim, gruzińskim, amharic, tigrinya, ladino, węgierskim, rumuńskim i rosyjskim;

6. „88 FM” - kanał prezentujący muzykę jazzową i bluesową, a także wiadomości drogowe;

7. „Kol haMusica” - kanał z muzyką klasyczną oraz teatrem radiowym;

8. „Reshet Moreshet” - kanał religijny, poświęcony judaizmowi, informujący o sprawach związanych z życiem religijnym Izraela.

W Izraelu funkcjonują również dwa radia przeznaczone dla społeczności Haredim: „Kol Chai”, powstałe w 1996 r., oraz „Kol ba-Rama”, założone w 2009 r. Oba prezentują wiadomości polityczne i społeczne z punktu widzenia judaizmu ultraortodoksyjnego. W obu audycje nadawane są z Bnei Brak, codziennie, oprócz szabatu (okres od wieczoru w piątek do wieczoru w sobotę).

Innymi radiami tematycznymi są np. „Galaei Tzahal” i „Arutz Sheva”. Pierwsze z nich funkcjonuje od 1950 r. i jest radiem Narodowych Sił Obronnych Izraela. Mimo tego większość słuchaczy stanowią cywile ${ }^{28}$. Radio nadaje audycje na dwóch kanałach 24 godziny na dobę. W audycjach pierwszego kanału prezentowane są bieżące wiadomości oraz talk-show, natomiast $\mathrm{w}$ drugim - muzyka i informacje drogowe. "Arutz Sheva” jest natomiast radiem religijnym, słuchanym przez społeczność ortodoksyjną. Prezentowane są w nim wiadomości polityczne, ekonomiczne oraz społeczne.

Pomimo tego, że w Izraelu każda radiostacja musi mieć zezwolenie na prowadzenie działalności, istnieją też stacje pirackie. Jedną z nich była „Voice of Peace”, funkcjonująca w latach 1973-1993, znana również w Europie. Niektóre z obecnie działających nielegalnych stacji są nawet finansowane z reklam ${ }^{29}$.

Liczba zarejestrowanych odbiorników telewizyjnych w Izraelu wynosi 1690 tys., co oznacza, że na 1000 mieszkańców telewizor posiada ok. 285 osób ${ }^{30} .1147$ tys. odbiorców korzysta z telewizji kablowej, a 1160 tys. — z telewizji satelitarnej ${ }^{31}$. Oznacza to, że duża część odbiorców cieszy się z obu możliwości odbioru telewizji. Przeważnie kanały telewizyjne w Izraelu są transmitowane z wykorzystaniem standardów Digital Video Broadcasting (DVB). Dla przykładu telewizja kablowa jest dostarczana przez

\footnotetext{
28 OECD, op. cit.

${ }^{29}$ Press Reference, op. cit.

${ }^{30}$ Ibidem.

${ }^{31}$ Ibidem.
} 
firmę telekomunikacyjną Hot z wykorzystaniem standardu DVB- $\mathrm{C}^{32}$, a telewizja satelitarna - przez firmę Yes z wykorzystaniem standardów DVB-S oraz DVB-S2 ${ }^{33}$.

Wspomniane firmy telekomunikacyjne Hot i Yes są głównymi dostawcami telewizji w Izraelu. Pierwsza z nich istnieje od 2003 r. i należy do holenderskiej firmy Altice. Powstała w wyniku połączenia trzech wcześniej działających na rynku dostawców telewizji kablowej - Matav, Tevel i Arutzei Zahav. Zajmuje się nie tylko dostarczaniem telewizji, lecz także szerokopasmowego Internetu i świadczeniem usług telekomunikacyjnych, zarówno dla klientów indywidualnych, jak i biznesowych. Użytkownicy Hot mają dostęp do ok. 200 kanałów hebrajskojęzycznych i zagranicznych, w tym kilkudziesięciu własnej marki. Jednym z nich jest „Hot 3”, oferujący rozrywkowe programy produkcji izraelskiej i amerykańskiej. Z kolei firma Yes istnieje od $2000 \mathrm{r}$. i jest własnością izraelskiej grupy telekomunikacyjnej Bezeq. Działa na terenie całego Izraela jako dostawca telewizji satelitarnej, Internetu i usług telekomunikacyjnych. W ofercie telewizyjnej ma 882 kanały izraelskie i zagraniczne, w jakości standardowej oraz HD. Należą do nich m.in. „Yes Drama” - emitujący programy rozrywkowe, „Yes Comedy” - emitujący filmy i seriale komediowe, „Yes Action” z filmami akcji, thrillerami i programami rozrywkowymi, „Yes Oh” — nadający amerykańskie i brytyjskie seriale, a także popularne na całym świecie kanały BBC, CBS, MTV i inne.

Przed rozwiązaniem Israel Broadcasting Authority pięć kanałów telewizyjnych było emitowanych drogą naziemną. Były to "Channel 1", "Channel 2", „Channel 10", „Channel 33” oraz „Knesset Channel”. Wszystkie były emitowane w jakości standardowej oraz HD. Kanały publiczne „1”, „33” oraz „Knesset”, podobnie jak radio „Kol Israel”, były zarządzane przez IBA. Kanały „2” i „10”, jako stacje komercyjne, znajdowały się pod kontrolą The Second Authority for Television and Radio (SBA). "Channel 1" emitował programy rozrywkowe (m.in. Cleaning the head, The coop group i This is my secret), sportowe (np. First goal, Saturday's game i Sports broadcast), młodzieżowe (przykładowo Animals and smiles, Jinji i The last vication), sitcomy (m.in. HaMisada haGdola, So what? i Straight to the point) oraz programy kulturalne (takie jak Ad pop, Mad in Israel i What a life), a także kilkadziesiąt programów importowanych zza granicy. „Channel 33” był przeznaczony dla społeczności arabskiej żyjącej w Izraelu. Prezentował programy informacyjne, rozrywkowe oraz kulturalne, emitowane w języku arabskim. „Knesset Channel” nadawał obrady Knesetu, czyli izraelskiego parlamentu. W 2017, po powołaniu Israeli Broadcasting Corporation, zdecydowano się na kontynuację działalności dwóch kanałów IBA - informacyjno-kulturalnego „Kan 1” i skierowanego do społeczności arabskiej „Kan 33”. „Channel 2", który prowadził działalność dzięki dwóm koncesjonariuszom - firmom Keshet i Reshet, powstałym w 1993 r., został podzielony na "Channel 12”, należący do

32 Digital Video Broadcasting Cable - standard umożliwiający transmisję telewizji w sieci kablowej.

${ }^{33}$ Digital Video Broadcasting Satellite i Satellite 2 - standardy umożliwiające satelitarną transmisję telewizji. 
Keshet, oraz "Channel 13”, podlegający Reshet. Programy emitowane na ich antenie to głównie seriale, talk-show i programy rozrywkowe. "Channel 14” (do $2017 \mathrm{r}$. "Channel 10"), choć znajduje się pod kontrolą SBA, należy do RGE Media Group. Podobnie jak „Channel 12" i „Channel 13”, emituje głównie programy rozrywkowe i seriale, w tym swoje oryginalne produkcje, takie jak Hacaverim Shel Naor, Achat Efes Efes, Ahava ze Koev czy Karov Levadai.

Oprócz wymienionych w Izraelu działają również:

- komercyjny „Channel 20”, poświęcony życiu żydowskiemu;

— „Music 24”, prezentujący muzykę popularną;

- rosyjskojęzyczne kanały informacyjne „Israel Plus” i „Israel Plus International”;

- pełniący funkcje dydaktyczne publiczny kanał „Israeli Educational Television”;

— arabskojęzyczny „Hala TV”.

Wśród portali informacyjnych w Izraelu mona wymienić te, które są internetowymi wydaniami mediów tradycyjnych, czyli wspomniane już serwisy: Al-Arab.net, Aljabha.org, Calcalist.co.il, Hamodia.com, Haaretz.com, Israelnationalnews.com, Jpost.com, Maariv.co.il oraz Makorrishon.co.il. Funkcjonują też samodzielne portale internetowe. Popularność stron internetowych określają rankingi tworzone przez serwis Alexa.com, biorące pod uwagę dzienną liczbę użytkowników odwiedzających stronę oraz liczbę wyświetleń w ostatnim miesiącu.

Portal „Ynet” (ynet.co.il) należy do grupy Yedioth Ahronot. Został założony w 2000 r. Znajdują się w nim elektroniczne wersje magazynów „LaIsha”, „Pnai Plus”, „Blazer”, „Go Magazine” i „Mentha”, co świadczy o szerokim zakresie tematycznym publikowanych treści. W 2004 r. powstała anglojęzyczna edycja portalu — „Ynet News" przez pewien czas istniała również edycja arabskojęzyczna. W rankingu popularności Alexa w maju 2016 r. serwis zajmował piąte miejsce.

„Walla!” (walla.co.il) to portal założony w 1995 r. przez Ereza Pilosofa i Gadiego Hadara. Prezentuje wiadomości z Izraela i ze świata 24 godziny na dobę. Mimo że od 2006 r. portal posiada niezależną redakcję, niektóre publikowane teksty pochodzą z mediów należących do Haaretz Group. Użytkownicy odwiedzający portal „Walla!” znajdują na nim informacje dotyczące polityki, spraw społecznych, kina, muzyki, mody, sportu i żywienia. Ponadto serwis oferuje dostęp do poczty, czatu, forów dyskusyjnych, wirtualnej galerii sklepów internetowych oraz encyklopedii - Walla!pedia, czerpiącej bazę haseł z hebrajskojęzycznej Wikipedii. W rankingu popularności Alexa w maju 2016 r. „Walla!” zajął siódme miejsce.

W 2012 r. były redaktor naczelny „The Jerusalem Post”, David Horowitz, założył portal informacyjny „The Times of Israel” (timesofisrael.com). Serwis Horowitza jest prowadzony w czterech językach: angielskim, arabskim, chińskim i francuskim. Redaktorami naczelnymi tych edycji są odpowiednio: David Horowitz, Suha Halifa, Li Jingjing i Stephanie Bitan. Portal jest całkowicie neutralny politycznie, co potwierdzają słowa jego założyciela: 
Jesteśmy niezależni; nie jesteśmy związani z żadną partią polityczną. The Times of Israel jest niezależnym, bezstronnym dziennikarskim przedsięwzięciem, i myślę, że to niesamowicie ważne przekazywać ludziom sens opcji, które uznaje Izrael, oraz stworzyć opartą na wiedzy i konstruktywną debatę ${ }^{34}$.

Teksty publikowane w „The Times of Israel” dotyczą polityki na Bliskim Wschodzie, spraw społecznych i kulturalnych. Dodatkowo portal zawiera platformę blogową. W rankingu popularnoci Alexa w maju 2016 r. serwis zajmował 218. miejsce.

Od 2002 r. funkcjonuje założony przez Rana Baratza magazyn internetowy „Mida” (mida.org.il). Publikacje w językach angielskim i hebrajskim dotyczą bieżących spraw politycznych i społecznych, ekonomii, kultury, edukacji, historii i religii. Redakcja określa się jako „klasycznie liberalną” lub „konserwatywnie liberalną”. Redaktorem naczelnym jest Akiva Bigman, a wśród dziennikarzy współpracujących z portalem wymienić można m.in. Erica Greensteina, Amnona Lorda, Ereza Tadmora i Boaza Leviego. W rankingu popularnoci Alexa w maju 2016 r. serwis zajmował 1013. miejsce.

W czerwcu 2000 r. dziennikarki Giora Shamis i Diane Shalem założyły portal „Debka File” (debka.com). Jest to serwis militarny, zawierający informacje, komentarze i analizy na temat bezpieczeństwa narodowego, stosunków międzynarodowych, bezpieczeństwa w Izraelu i na Bliskim Wschodzie oraz terroryzmu. Reklamuje się sloganem: We start, when the media stop. Teksty publikowane są w językach angielskim i hebrajskim. Amerykański „Forbes” docenił portal „Debka File” za najlepsze archiwum, jednoczenie zarzucając mu, że większość informacji pochodzi z niesprawdzonych źródeł. W rankingu popularności Alexa w maju 2016 r. serwis zajmował 1826. miejsce.

Społeczność Haredim korzysta również z serwisu „Kikar ha-Shabbat” (kikar.co.il). Strona została założona w 2009 r. przez ultraortodoksyjnego dziennikarza Mordechaja Laviego. Nazwa portalu nawiązuje do ulicy w Jerozolimie, zamieszkałej przez społeczność Haredim. Publikowane są na nim informacje polityczne i społeczne w języku hebrajskim. Redaktorem naczelnym jest Chaim Illouz.

Jak dowodzi niniejsza praca, system medialny w Izraelu jest ciekawie skonstruowany. Biorąc pod uwagę, że podczas tworzenia artykułu korzystałem ze źródeł anglo- i hebrajskojęzycznych, muszę stwierdzić, że brakuje polskojęzycznej literatury dotyczącej izraelskich mediów. Studenci dziennikarstwa w Polsce poznają systemy medialne krajów europejskich czy Stanów Zjednoczonych, jednak uwagi nie poświęca się niestety mediom na Bliskim Wschodzie, co uznaję za dużą stratę. Uważam bowiem, że izraelski system medialny może stanowić wzór w świecie mediów.

34 J. Nathan-Kazis, The softspoken man behind Times of Isreael, 19.02.2012, http://forward.com/ news/152169/thesoftspoken-man-behind-times-of-isreael (dostęp: 4.04.2018). 


\section{The media system in Israel today}

\section{Summary}

The paper examines the media system in the state of Israel. It takes into account both the history of the media - from the press through radio and television to the internet - and the current situation. The author describes the most important Israeli media: newspapers, television and radio stations, as well as websites, taking into consideration their popularity on the market, political orientation and importance in Israel's media world. 